\title{
Vai trò của đất sản xuất đối với việc xóa đói giảm nghèo ở khu vực Tây Nguyên
}

\section{The role of production land in poverty reduction in the Central Highlands}

\author{
Nguyễn Văn Dư ${ }^{1 *}$ \\ ${ }^{1}$ Trường Đại học Mở Thành phố Hồ Chí Minh, Việt Nam \\ "Tác giả liên hệ, Email: du.nv@ou.edu.vn
}

THÔNG TIN

DOI:10.46223/HCMCOUJS. econ.vi.13.3.1513.2018

Ngày nhận: 10/01/2018

Ngày nhận lại: 15/05/2018

Duyệt đăng: 10/07/2018

Tù khóa:

đất sản xuất, mô hình logit nhị phân, nghèo đói ở Tây Nguyên, xóa đói giảm nghèo

Keywords:

production land, binary logistic model, poverty in the Central Highlands, poverty reduction

\section{TÓM TÁT}

Bài báo sử dụng bộ số liệu điều tra của Tổng cục Thống kê và mô hình logit nhị phân nhằm tìm hiểu các yếu tố ảnh hưởng đến quá trình thoát nghèo ở Tây Nguyên và thoát nghèo trên phạm vi cả nước để so sánh sự khác biệt. Kết quả nghiên cứu cho thấy, trong giai đoạn 2001 đến 2014, có 5 yếu tố ảnh hưởng, bao gồm: tuổi và giới tính của chủ hộ; trình độ học vấn cao nhất của các thành viên trong gia đình; dân tộc học; và sự hỗ trợ của Chính phủ. Đặc biệt, nghiên cứu đã tìm thấy bằng chứng khác biệt đó là việc sở hữu đất sản xuất có ảnh hưởng tới quá trình thoát nghèo ở khu vực Tây Nguyên nhưng trên phạm vi cả nước thì tác động của yếu tố này là không có ý nghĩa về mặt thống kê.

\section{ABSTRACT}

This paper examines the factors affecting the process of poverty reduction in the Central Highlands region and across the country by comparing the difference between the two regions over the period 2001-2014. The binary logistic model is employed and the data is collected from the General Statistics Office of Vietnam. The results indicate that there are five factors influencing the process of poverty reduction including the age and gender of the household head; the highest educational level of family members; ethnography; and the supports from Vietnamese Government variables. It can also be concluded that the production land ownership variable has a significant effect on the process of poverty reduction for the Central Highlands region of Vietnam. However, the impact of this factor is not statistically significant for the whole country. 


\section{Giới thiệu}

Đói nghèo là tính trạng các cá nhân trong hộ gia đình thiếu nguồn lực để duy trì một cuộc sống với các tiêu chuẩn tối thiểu về cả lương thực, thực phẩm và những thiết yếu khác (UNDP, 2012). Thước đo tiêu chuẩn đói nghèo phụ thuộc vào điều kiện sống, sức mua hàng hóa của người dân địa phương dẫn đến ngưỡng đói nghèo cũng khác nhau và có sự thay đổi theo các quốc gia và theo thời gian. Hiện nay vấn đề đói nghèo vẫn được xem là nghiêm trọng khi có tới 1/4 dân số trên thế giới đang sống trong tình trạng đói nghèo (World Bank, 2015). Đói nghèo không chỉ làm cho nhiều người rơi vào tình trạng thiếu thốn, đói khổ, không được tận hưởng những thành quả về sự tiến bộ, văn minh của loài người mà còn có thể gây ra nhiều hậu quả nghiêm trọng về kinh tế, xã hội, tàn phá môi trường sinh thái và thậm chí là chiến tranh, xung đột.

Xóa đói giảm nghèo là một quá trình đòi hỏi nhiều nỗ lực của các bên liên quan bởi việc cải thiện thu nhập, nâng cao mức sống về mọi mặt của một nhóm dân cư không phải là một việc làm đơn giản. Ngay cả khi thoát được nghèo, nếu không duy trì được sự cải thiện bền vững, thì cũng có thể rơi vào tình trạng tái nghèo.

Cũng như các quốc gia đang phát triển khác trên thế giới, tình trạng đói nghèo ở Việt Nam đã và đang là những thách thức đối với Chính phủ và chính quyền ở một số địa phương. Số liệu từ Tổng cục thống kê (TCTK) cho thấy, năm 1993, tỷ lệ hộ đói lên đến 51,8\%, tức hơn một nửa dân số sống trong nghèo đói. Với ý chí vươn lên của các hộ gia đình, sự quyết tâm của Chính phủ, sự hỗ trợ của bạn bè quốc tế chúng ta đã đạt những thành tựu nhất định trong cuộc chiến xóa đói-giảm nghèo. Sau gần 20 năm, kể từ 1993, tỷ lệ đói nghèo trên cả nước đã giảm xuống còn $9,6 \%$. Tuy nhiên, tỷ lệ đói nghèo ở khu vực Tây Nguyên vẫn còn $15 \%$, cao hơn so với cả nước. Đặc biệt, tỷ lệ hộ nghèo ở Kon Tum lên đến 22,77\% (Tổng cục Thống kê, 2014).

Đất sản xuất có vai trò quan trọng đối với người nghèo và quá trình xóa đói, giảm nghèo. Phần lớn những hộ nghèo sống ở nông thôn, miền núi, hải đảo và sống bằng nông nghiệp. Chính vì vậy các chương trình xóa đói giảm nghèo thường gắn với những chính sách về đất đai và quá trình sản xuất nông nghiệp chẳng hạn như giao đất sản xuất cho nông dân, chuyển dịch cơ cấu kinh tế nông nghiệp theo hướng sản xuất hàng hóa, tăng cường liên kết, tìm thị trường tiêu thụ sản phẩm, etc... nhằm giúp người nghèo mở rộng thị trường nâng cao giá trị hàng hóa sản xuất. Ngoài chính sách đất đai, đôi khi những hộ thuộc diện đói nghèo còn nhận được sự hỗ trợ của Chính phủ hoặc các tổ chức khác về tiền mặt, hoặc hiện vật.

Mục tiêu của bài báo là tìm hiểu một số yếu tố, trong đó đặt trọng tâm vào việc phân tích về tác động của sở hữu đất sản xuất nông nghiệp ở khu vực Tây Nguyên, có ảnh hưởng tới quá trình xóa đói giảm nghèo.

\section{Co’ sở lý thuyết}

\subsection{Khái niệm đói nghèo}

Đói nghèo là một khái niệm mang tính tương đối, có thể biến đổi theo thời gian, theo vùng miền và theo từng quốc gia. Tuy nhiên, quan điểm về đói nghèo đều xoay quanh những vấn đề: (1) mức sống thấp hơn mức sống trung bình của cộng đồng dân cư; (2) không được thụ 
hưởng những nhu cầu cơ bản ở mức tối thiểu; (3) thiếu cơ hội lựa chọn tham gia vào phát triển cộng đồng.

Theo tổ chức $\mathrm{Y}$ tế thế giới, một người là nghèo khi thu nhập hàng năm ít hơn $1 \frac{1}{2}$ thu nhập bình quân trên đầu người (PCI: Per Capita Income) ở địa phương họ sinh sống. Liên Hợp Quốc đánh giá tình trạng đói nghèo dựa vào mức sống của con người thông qua ba tiêu chí đó là thu nhập, thành tựu y tế - xã hội và trình độ văn hóa giáo dục. Còn theo Ủy ban Kinh tế và Xã hội của châu Á - Thái Bình Dương (ESCAP) thì tình trạng đói nghèo là tình trạng một bộ phận dân cư không có khả năng đáp ứng những nhu cầu cơ bản của con người mà những nhu cầu này đã được xã hội, nơi mà họ sinh sống thừa nhận.

Theo quan điểm của Việt Nam, đói nghèo là tình trạng của một bộ phận dân cư không được thụ hưởng hoặc thỏa mãn những nhu cầu cơ bản của con người mà những nhu cầu này đã được xã hội và địa phương họ cư trú thừa nhận. Như vậy, tình trạng đói nghèo không chỉ là vật chất mà còn cả văn hóa, tinh thần.

Trong bài báo này, tác giả dựa vào tiêu chuẩn đói nghèo được Tổng cục thống kê áp dụng chỉ thuần túy là dựa vào phạm trù vật chất. Cụ thể, tính theo chuẩn nghèo của Chính phủ giai đoạn 2011-2015 là 400 nghìn đồng/người/ tháng đối với khu vực nông thôn và 500 nghìn đồng/người/tháng đối với khu vực thành thị.

\subsection{Xóa đói giảm nghèo}

Xóa đói giảm nghèo là làm cho một bộ phận dân cư nghèo phát triển kinh tế, cải thiện thu nhập, nâng cao mức sống và từng bước thoát khỏi tình trạng đói nghèo. Đây là nhiệm vụ cần làm thường xuyên và cần có sự quan tâm của các tổ chức trong xã hội bởi ngay cả khi thoát được nghèo cũng có thể rơi vào tình trạng tái nghèo.

Sản xuất, đầu tư, dẫn đến tăng trưởng kinh tế là những nhân tố quan trọng và có tác động mạnh đến tình trạng xóa đói giảm nghèo. Khi người dân gia tăng thu nhập thì nhiều vấn đề kinh tế-xã hội liên quan đến đói nghèo như y tế, giáo dục, tuổi thọ, etc., ... được cải thiện.

Các nhà kinh tế học đã mô tả sản xuất là quá trình biến đổi các yếu tố đầu vào thành các yếu tố đầu ra thông qua một trình độ công nghệ nhất định. Quá trình sản xuất được các nhà kinh tế học mô tả bằng hàm sản xuất. Theo Begg (1991) hàm sản xuất $q=f(K, L)$ của một loại sản phẩm nào đó cho biết số lượng sản phẩm tối đa của sản phẩm đó (ký hiệu là q) có thể được sản xuất ra bằng cách sủ dụng các phối hợp khác nhau của vốn $(K)$ và lao động $(L)$, với một trình độ công nghệ nhất định. Trong hàm sản xuất, vốn có thể tồn tại ở nhiều dạng như vốn tài chính, máy móc, trình độ công nghệ, tư liệu sản xuất, etc... Ở Việt Nam, phần lớn những hộ gia đình nghèo sống ở nông thôn, miền núi, và sống bằng sản xuất nông nghiệp. Chính vì vậy đất sản xuất trở thành nguồn vốn quan trọng, nguồn tư liệu cần thiết trong hoạt động sản xuất, mưu sinh của hộ nghèo.

Ngoài yếu tố phát triển sản xuất, tăng trưởng kinh tế, công tác xóa đói giảm nghèo còn phụ thuộc vào nguyên nhân gây ra tình trạng đói nghèo. Thực tiễn và nhiều công trình nghiên cứu cho thấy có nhiều nguyên nhân, bao gồm cả những nguyên nhân chủ quan, khách quan hay những vấn đề xã hội có ảnh hưởng tới tình trạng đói nghèo cũng như ảnh hưởng tới việc xóa đói giảm nghèo. Thông thường, người nghèo có trình độ học vấn và kỹ năng nghề nghiệp thấp, 
quy mô hộ gia đình đông, nhiều người phụ thuộc, etc... vì vậy, đối với những nguyên nhân chủ quan này thì cần yếu tố phấn đấu nội lực, ý chí vươn lên của chính hộ gia đình, tránh tình trạng chây ỳ, tâm lý ỷ lại. Đối với những nguyên nhân khách quan như ốm đau, bệnh tật, thiên tai, dịch bệnh, vị trí địa lý xa trung tâm, khí hậu khắc nghiệt, vấn đề bình đẳng giới, etc., thì cần có sự trợ giúp, chung tay của cộng động. Trong khi đó, những nguyên nhân thuộc về thể chế, chính sách, hay những vấn đề xã hội như y tế, giáo dục, nhà ở, nước sinh hoạt, etc... thì cần có sự hỗ trợ của Chính phủ và các tổ chức đoàn thể thông qua các chương trình mục tiêu, những chính sách vĩ mô nhằm giúp các hộ gia đình thoát nghèo.

\subsection{Các nghiên cúu có liên quan}

Đói nghèo là vấn đề xã hội được nhiều nhà khoa học quan tâm, nghiên cứu ở những thời điểm, nơi chốn khác nhau. Nghiên cứu của Cunguara (2008) về xóa đói giảm nghèo ở khu vực nông thôn của Mozmbique đã chỉ ra nhiều yếu tố ảnh hưởng tới việc thoát nghèo như vấn đề sở hưu đất đai, đa dạng hóa trong hoạt động nông nghiệp bằng cách kết hợp chăn nuôi, trồng trọt, etc... Kết quả này cũng phù hợp với nghiên cứu của Reardon (1997) thực hiện. Reaedon còn nhấn mạnh tầm quan trọng của thu nhập phi nông nghiệp trong việc giảm nghèo. Kết quả nghiên cứu của tác giả Otsuka, Estudillo, và Yamano (2007) cũng đã chỉ ra nhiều yếu tố có ảnh hưởng tới việc xóa đói giảm nghèo, trong đó, nhóm tác giả nhấn mạnh yếu tố vốn, sở hưu đất đai và trình độ của người chủ hộ. Nghiên cứu về giảm nghèo đói ở Nigeria, tác giả Amaka (2011) đã chỉ ra tác động của việc sở hưu đất đai cùng với các yếu tố như vốn tài chính, giới tính, tuổi của người chủ hộ, qui mô hộ gia đình có ảnh hưởng tới việc xóa đói giảm nghèo.

Trong nước cũng có nhiều nghiên cứu về chủ đề xóa đói giảm nghèo và mối quan hệ với việc sở hữu đất sản xuất. Dong và Chu (2017) trong bài báo "Nguyên nhân ảnh huởng tới thoát nghèo và tái nghèo của hộ nông dân huyện Đồng Hỷ, tỉnh Thái Nguyên", đã sử dụng mô hình logit đa thức để tìm ra nguyên nhân ảnh hưởng đến thoát nghèo và tái nghèo để từ đó đề xuất các giải pháp nhằm giảm nghèo bền vững. Kết quả hồi quy cho thấy các yếu tố bao gồm: trình độ học vấn; tỷ lệ thành viên phụ thuộc; diện tích đất sản xuất; thu nhập phi nông nghiẹp; dân tộc học; tình trạng việc làm có ảnh hưởng đến xác suất thoát nghèo. Kết quả này cũng tương đồng với nghiên cứu của T. C. Tran (2007) trong đề tài nghiên cứu cấp Bộ "Thưc trạng và giải pháp xóa đói giảm nghèo cho đồng bào dân tộc vùng núi cao tỉnh Thái Nguyên". Đề tài nghiên cứu cấp Bộ của $\mathrm{H}$. T. Nguyen (2005), "Nghiên cưu ứng dụng các mô hình kinh tế lượng phân tích các nhân tố tác đọng đến nghèo đói và đề xuất xóa đói giảm nghèo ở các tỉnh Đông Nam Bộ". Trong đề tài, tác giả Nguyễn Trọng Hoài và nhóm nghiên cứu đã khảo sát và thu thập số liệu từ 640 hộ nông dân ở Ninh Thuận và 619 hộ nông dân ở Bình Phước. Bằng việc sử dụng hàm hồi quy logit, tác giả và nhóm nghiên cứu đã chỉ ra các yếu tố diện tích đất canh tác, dân tộc học, tiếp cận vay vốn, etc... là những biến số có ý nghĩa thống kê để giải thích nguyên nhân và yếu tố ảnh hưởng tới nghèo đói của hộ nông dân. Ngoài ra còn có thể kể đến nhiều nghiên cứu về xóa đói giảm nghèo của các tác giả khác như: H. N. Tran (2011), N. T. Nguyen (2012), Do (2006), T. V. Nguyen (2004), Thai (2007), Mai (2007), etc... được thực hiện ở một số địa phương khác nhau. Hầu hết các tác giả chỉ ra nguyên nhân của tình trạng đói nghèo là do thiếu đất đai và vốn sản xuất, quy mô hộ gia đình đông, nhiều người sống phụ thuộc một số trường hợp là do tình trạng thiên tai, dịch bệnh. 


\subsection{Mô hình nghiên cúu và dũu liệu nghiên cứu}

\subsubsection{Mô hình nghiên cúu}

Nhiều tác giả sử dụng mô hình hồi quy logit trong nghiên cứu mà biến phụ thuộc là biến định danh, mang hai phạm trù. Một số mô hình có thể được sử dụng trong trường hợp biến phụ thuộc mang giá trị nhị nguyên như mô hình logit, probit, xác suất tuyến tính (LPM: Linear Probability Model) để phân tích hồi quy. Tuy nhiên mô hình LPM có thể xảy ra tình trạng phương sai không đồng nhất (heteroscedasticity) hoặc giá trị biến phụ thuộc nằm ngoài khoảng 0 và 1 (Gujarati, 2011; D. Q. Nguyen, 2002). Còn theo Gujarati thì hai mô hình logit và probit có phân phối khác nhau, dẫn đến xác suất để biến phụ thuộc tiệm cận về 0 và 1 là khác nhau, nhưng sự khác biệt này là không đáng kể. Do sự phổ biến và sự thuận tiện trong cách ước lượng nên trong bài báo này tác giả đã chọn mô hình logit để phân tích hồi quy.

Trong mô hình hồi quy logit, nếu gọi $\mathrm{P}$ là xác suất để một biến cố xảy ra thì 1-P sẽ là xác suất cho trạng thái còn lại, phương trình hồi quy logit với Xij là các biến độc lập có ảnh hưởng đến việc lựa chọn được định nghĩa:

$$
\log \left(\frac{p}{1-p}\right)=\beta_{1}+\beta_{2} X_{2 i}+\ldots .+\beta_{k} X_{k i}+\varepsilon
$$

Bằng việc khảo sát ở hai thời điểm, trong đó thời điểm đầu tác giả lựa chọn tất cả các hộ gia đình thuộc diện nghèo, sau thời gian 3 năm, các hộ gia đình có thể đã thoát nghèo $\mathrm{Y}_{\mathrm{i}}=1$ hoặc chưa thoát nghèo $\mathrm{Y}_{\mathrm{i}}=0$.

Cơ sở lý thuyết và các nghiên cứu trước cho thấy nhiều yếu tố có ảnh hưởng tới quá trình xóa đói giảm nghèo. Với mục tiêu của bài báo là tìm hiểu một số yếu tố ảnh hưởng đến xóa đói giảm nghèo, trong đó trọng tâm vào việc sở hữu đất sản xuất ở khu vực Tây Nguyên, biến giải thích của mô hình sẽ bao gồm:

Diện tích đất sản xuất (DT_DAT_SX) đất đai là phương tiện sản xuất, có vai trò quan trọng, đặc biệt, đối với người dân ở Tây Nguyên, nơi mà đa số người dân sống bằng nghề trồng cây công nghiệp lâu năm. Trong mô hình biến sẽ được đo theo $\mathrm{m}^{2}$ và kỳ vọng có dấu (+) với xác suất thoát nghèo.

Tuổi (TUOI): Tuổi của người chủ hộ gia đình gắn liền với kinh nghiệm sản xuất. Tuy nhiên, tuổi cao cũng gắn với sự thiếu nhạy bén, thiếu linh hoạt và khả năng tiếp cận thị trường dẫn đến nhiều quyết định trong việc đầu tư kém hiệu quả. Trong mô hình biến này được kỳ vọng có quan hệ nghịch biến với biến phụ thuộc.

Giới tính (G_TINH): Giới tính của chủ hộ gia đình có thể có ảnh hưởng tới những quyết định sản xuất, kinh doanh, làm kinh tế hộ, chẳng hạn: những người chủ hộ gia đình là nam giới thường mạnh mẽ, quyết đoán. Mô hình dùng biến giả với qui ước nam $=1 /$ nữ $=0$ và được kỳ vọng dấu (+).

Thành thị nông thôn (TT_NT): Ở khu vực nông thôn hoặc vùng sâu, vùng xa thường có kinh tế kém phát triển, cơ hội tìm việc cũng khó khăn, sản phẩm làm ra khó tiếp cận thị trường và điều đó làm cho xác suất thoát nghèo ở khu vực này cũng có thể có thấp hơn. Tác giả dùng biến giả với qui ước thành thị $=1 /$ nông thôn $=0$ và kỳ vọng có dấu $(+)$. 
Dân tộc thiểu số (D_TOC): Những người thuộc dân tộc thiểu số thường cư trú ở những vùng sâu, vùng xa, địa hình hiểm trở. Đồng thời, tập quán kinh doanh, trình độ dân trí thấp là nguyên nhân làm cho tình trạng đói nghèo tăng cao hơn so với cộng đồng người Kinh. Biến D_TOC $=1$ cho biết người được khảo sát là dân tộc thiểu số và kỳ vọng có quan hệ nghịch dấu với biến phụ thuộc.

Thành viên phụ thuộc (TV_PHU_THUOC): Những hộ gia đình đông thành viên sẽ có khả năng làm kinh tế tốt hơn so với những hộ đơn thân. Tuy nhiên, nếu là thành viên phụ thuộc như trẻ em, người già, người mất khả năng lao động thì sẽ có tác động ngược lại.

Trình độ cao nhất của cá nhân trong hộ (TD_C_NHAT): Trình độ gắn liền với khả năng suy tính, đầu tư, quan hệ xã hội, etc... Việc làm kinh tế hộ gia đình không chỉ phụ thuộc vào người chủ hộ mà có thể những người có trình độ cao trong gia đình sẽ có ảnh hưởng tới việc sắp, ra quyết định sản xuất, kinh doanh. Trong mô hình này, trình độ được đo theo bằng cấp của thành viên và chọn trình độ cao nhất của các thành viên trong hộ, kỳ vọng dấu (+).

Hỗ trợ của các tổ chức (HO_TRO): Sự hỗ trợ của các tổ chức là rất cần thiết trong việc xóa đói giảm nghèo, nhất là trong những trường hợp các hộ có mức thu nhập quá thấp so với chuẩn nghèo hoặc gặp rủi ro như thiên tai, dịch bệnh, ốm đau. Xét ở khía cạnh khác, việc hỗ trợ bằng tiền mặt có thể gây ra tâm lý ỷ lại, không có ý thức vươn lên. Trong phạm vi nghiên cứu này, tác giả khảo sát ảnh hưởng của yếu tố này thông qua việc hỗ trợ bằng tiền và mối quan hệ có thể đồng biến/nghịch biến, phụ thuộc vào dữ liệu nghiên cứu.

\subsubsection{Dũ liệu nghiên cúu}

Nguồn dữ liệu chủ yếu được lấy từ bộ VHLSS. Khảo sát mức sống hộ gia đình VHLSS được Tổng cục thống kê tiến hành từ những năm 1993 với mục tiêu là thu thập thông tin của hộ gia đình và địa phương (xã, phường). Thông tin thu được là cơ sở để phân tích đánh giá mức sống, tình trạng và mức độ phân hóa giàu nghèo, từ đó hoạch định chính sách, xây dựng chương trình mục tiêu quốc gia nhằm nâng cao mức sống dân cư trong cả nước. Bộ số liệu VHLSS các năm chủ yếu phản ánh (1) mức sống của hộ gia đình và (2) điều kiện kinh tế xã hội cơ bản của địa phương theo đơn vị xã, phường có tác động đến mức sống của người dân nơi họ sinh sống. Đây là bộ số liệu khảo sát ở qui mô quốc gia và do một tổ chức của Chính phủ thực hiện.

Nghiên cứu này sử dụng bộ số liệu VHLSS khảo sát vào các năm 2010, 2012 và trọng tâm là bộ VHLSS 2014. Do công tác xóa đói giảm nghèo cần có khoảng thời gian để đánh giá, đồng thời, vào năm 2011 thì chuẩn nghèo của Việt Nam được điều chỉnh theo chương trình mục tiêu quốc gia Giảm nghèo bền vũng giai đoạn 2012-2016, vì vậy, tác giả đã chọn khoảng thời gian 2011-2014 để phân tích hồi quy.

\section{Kết quả nghiên cứu}

\subsection{Kết quả thống kê}

Về địa lý, Tây Nguyên gồm 5 tỉnh, theo thứ tự vị trí địa lý từ Bắc vào Nam thì khu vực này gồm các tỉnh Kon Tum, Gia Lai, Đắk Lắk, Đắk Nông và Lâm Đồng với diện tích tự nhiên là $54.474 \mathrm{~km}^{2}$ chiếm 16,8\% diện tích tự nhiên cả nước. Đất đai ở khu vực Tây Nguyên rất trù phú với đa phần là đất đỏ bazan, thích hợp cho nhiều loại cây trồng như cây cao su, cà phê, chè, 
hồ tiêu, điều... và rừng; Đất đỏ vàng diện tích khoảng 1,8 triệu ha, kém màu mỡ hơn đất đỏ bazan nhưng giữ ẩm tốt và tơi xốp nên thích hợp với nhiều loại cây trồng. Tuy nhiên diện tích đất trống đồi núi trọc đang gia tăng, chiếm tới 1,4 triệu ha và đang bị thoái hóa nghiêm trọng. Ngoài ra khu vực này cũng có nhiều tài nguyên, khoáng sản. Tuy vậy đời sống kinh tế ở khu vực này còn khó khăn, mức thu nhập luôn thấp hơn so với mức thu nhập trung bình của cả nước.

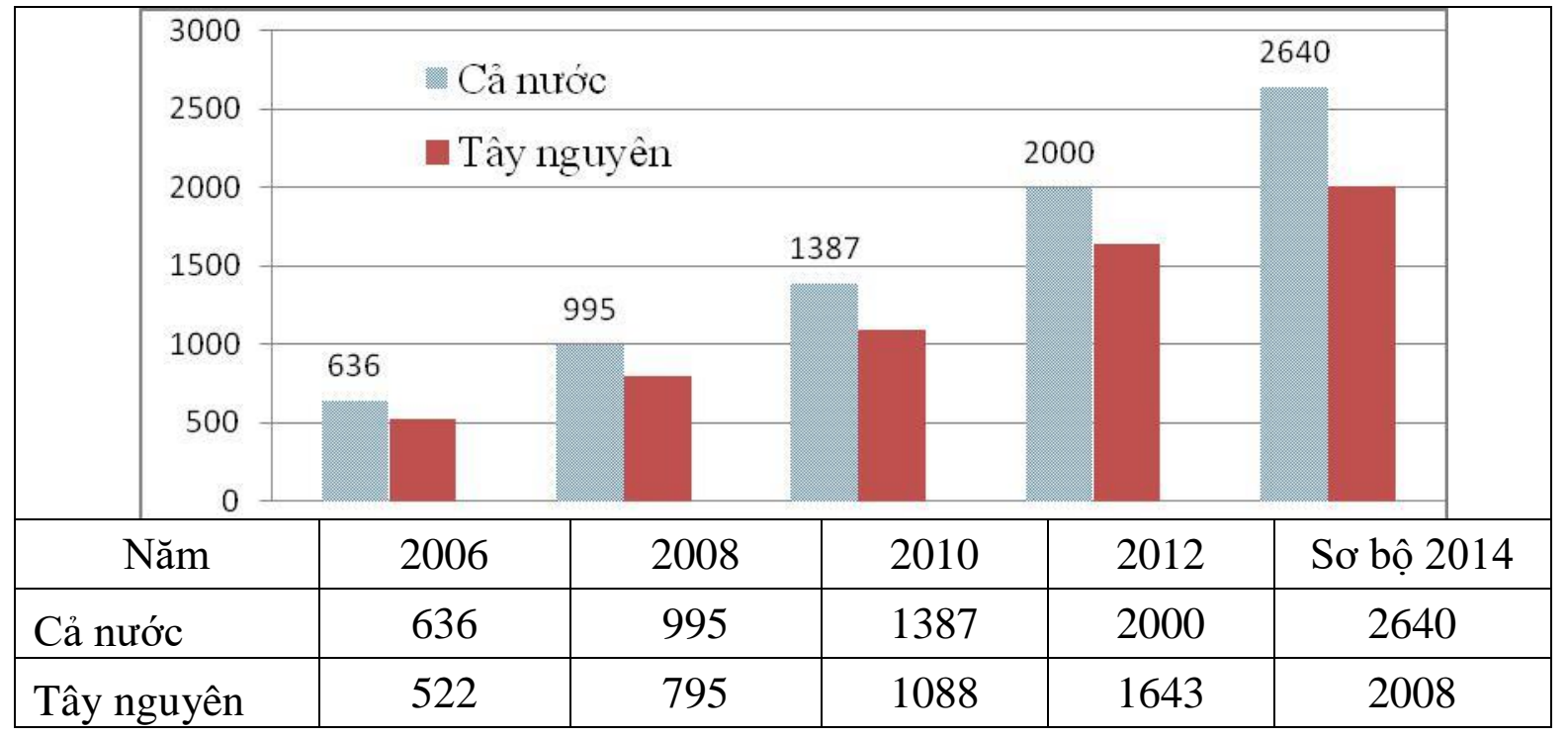

Hình 1. Biểu đồ thu nhập của hộ gia đình ở Tây Nguyên từ 2006 tới 2014

Nguồn: Điều tra mức sống hộ gia đình

Về tình hình đói nghèo, các tỉnh thuộc khu vực Tây Nguyên có tỷ lệ hộ đói nghèo cao hơn trung bình của cả nước. Theo số liệu thống kê, trong số 9399 hộ gia đình được khảo sát trên cả nước vào năm 2014 thì có 998 hộ thuộc diện đói nghèo, tương đương tỷ lệ $11 \%$. Tỷ lệ này ở Tây Nguyên là $14 \%$ và ngay trong khu vực Tây Nguyên, tỷ lệ hộ nghèo có sự chênh lệnh khá lớn. Theo đó, Lâm Đồng là địa phương có tỷ lệ đói nghèo thấp nhất trong khi Kon Tum có tỷ lệ này cao nhất khu vực.

\begin{tabular}{|c|c|c|c|c|c|c|c|c|}
\hline & $30 \%$ & & & & & & $26 \%$ & \\
\hline 武 & $25 \%$ & & & & & $19 \%$ & & \\
\hline z & 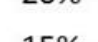 & & $14 \%$ & & $14 \%$ & & & \\
\hline$\stackrel{ㅇ .}{1}$ & $15 \%$ & $11 \%$ & & $9 \%$ & & & & \\
\hline 뙄 & $5 \%$ & & & & & & & $5 \%$ \\
\hline Е & & & & & & & & \\
\hline & & $\begin{array}{c}\text { Cả } \\
\text { nước }\end{array}$ & $\begin{array}{c}\text { Tây } \\
\text { Nguyên }\end{array}$ & $\begin{array}{l}\text { Đắk } \\
\text { Lắk }\end{array}$ & $\begin{array}{l}\text { Đăk } \\
\text { Nông }\end{array}$ & Gia Lai & $\begin{array}{l}\text { Kon } \\
\text { Tum }\end{array}$ & $\begin{array}{l}\text { Lâm } \\
\text { Đồng }\end{array}$ \\
\hline Tồng & tra & 9399 & 651 & 165 & 102 & 141 & 102 & 141 \\
\hline Đói N & & 998 & 90 & 15 & 14 & 27 & 27 & 7 \\
\hline Tỷ 1ệ & & $11 \%$ & $14 \%$ & $9 \%$ & $14 \%$ & $19 \%$ & $26 \%$ & $5 \%$ \\
\hline
\end{tabular}

Hình 2. Biểu đồ về tình trạng đói nghèo ở Tây Nguyên

Nguồn: Điều tra mức sống hộ gia đình 2014 
Khó khăn của những hộ đói nghèo là rất nhiều như thiếu thốn về lương thực, thực phẩm, hàng tiêu dùng, về nhà ở, v.v... So với mặt bằng chung của cả nước, ngoại trừ điện, những người nghèo ở Tây Nguyên gặp khó khăn hơn nhiều nếu so sánh theo một mặt hàng thiết yếu. Có tới $32 \%$ hộ nghèo ở Tây Nguyên không đủ thực phẩm, $20 \%$ hộ gia đình không đủ hàng tiêu dùng như quần áo, giày dép.

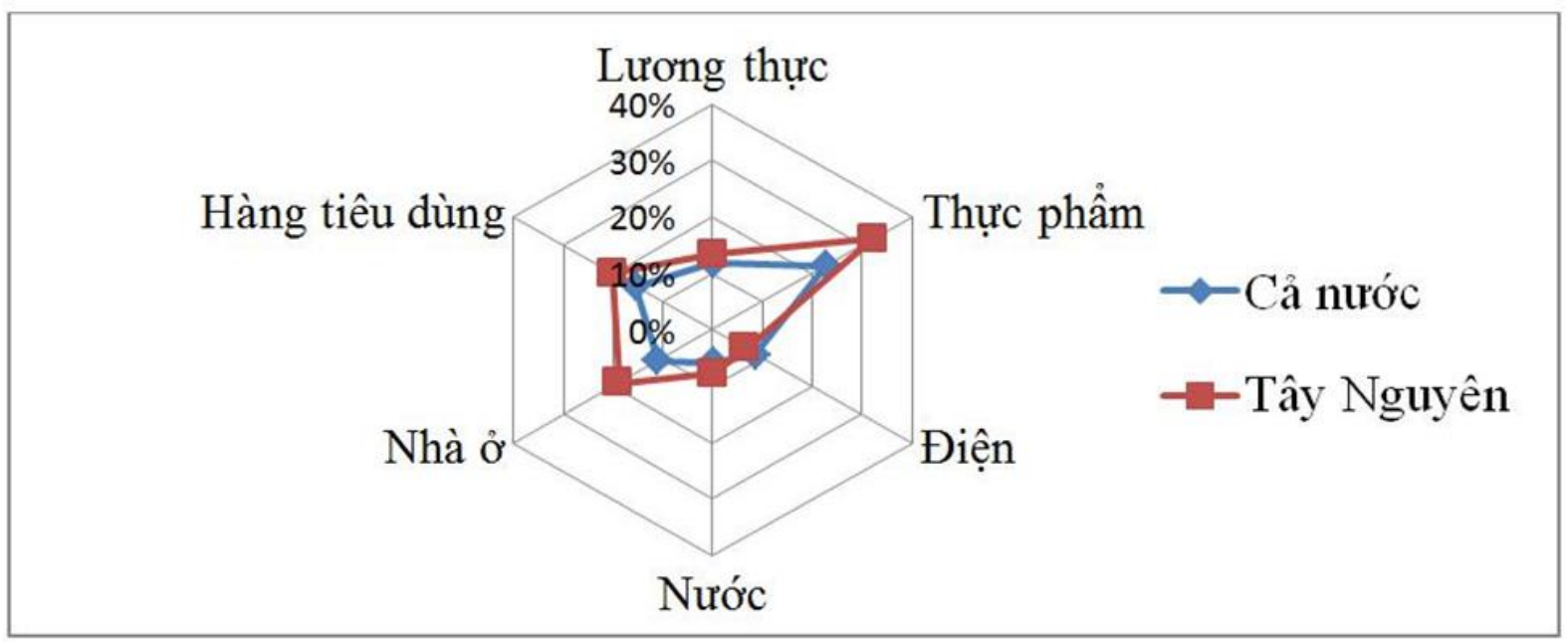

Hình 3. Biểu đồ về những khó khăn trước mắt của hộ nghèo

Nguồn: Điều tra mức sống hộ gia đình 2014

Do đa phần dân số ở đây sống bằng nghề trồng cây công nghiệp lâu năm, vì vậy số liệu từ TCTK về cơ cấu thu nhập của hộ gia đình cho thấy, ở đây, nguồn thu từ sản xuất nông nghiệp là chủ yếu, chiếm $43 \%$. Đặc biệt ở tỉnh Đắk Nông, thu từ sản xuất nông nghiệp chiếm tới 59\% tổng thu nhập của người dân.

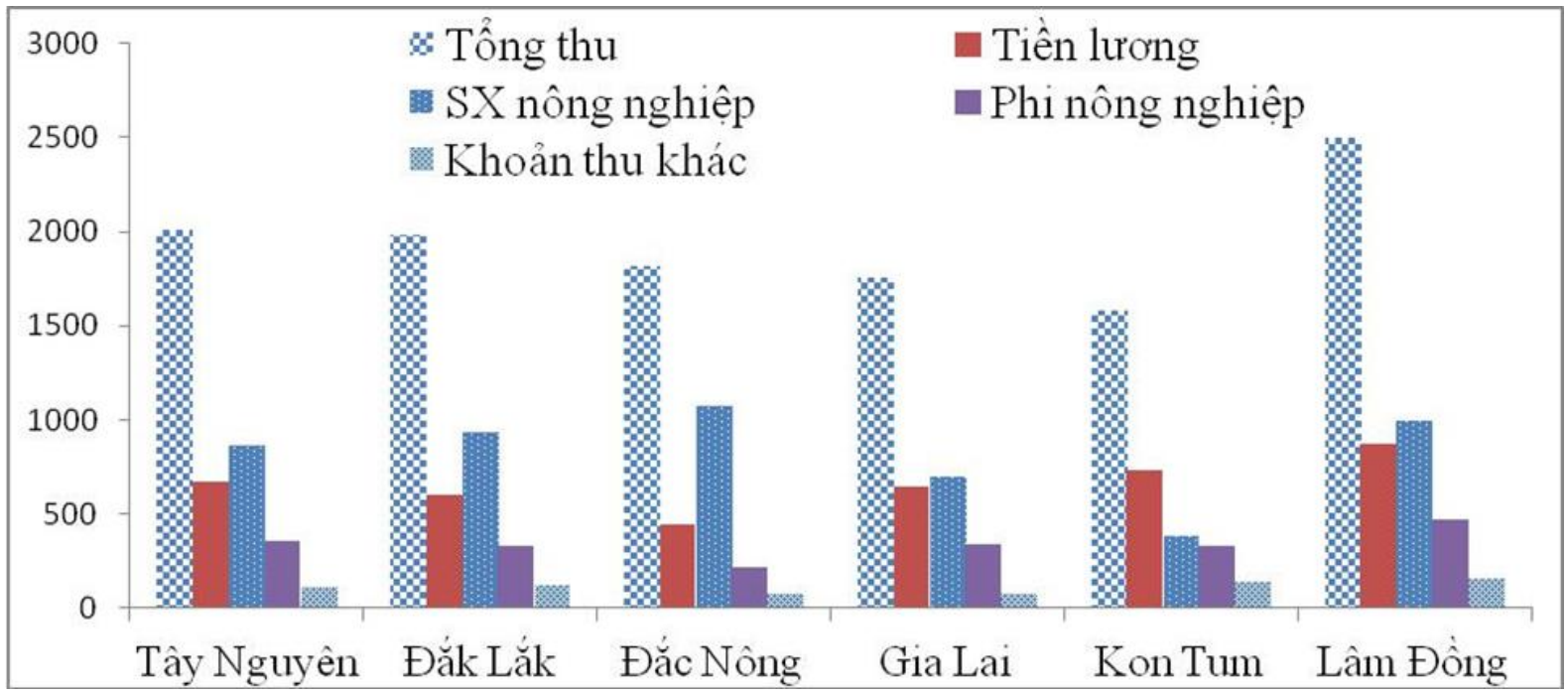

Hình 4. Biểu đồ nguồn thu nhập của hộ gia đình ở Tây Nguyên

Nguồn: Niên giám thống kê 2014 
Tình hình sở hữu đất sản xuất trên cả nước và khu vực Tây Nguyên càng minh chứng cho vai trò của việc sở hữu đất đai đối với thu nhập của người dân. Với thu nhập chủ yếu từ sản xuất nông nghiệp, việc không có đất sản xuất sẽ làm cho hộ gia đình khó mà có thể thoát khỏi nghèo nàn. Nếu trên phạm vi cả nước không có sự khác biệt về sở hữu đất sản xuất giữa nhóm những hộ gia đình nghèo và hộ gia đình không nghèo thì ở khu vực Tây Nguyên, sự khác biệt này là rất rõ ràng. Nhưng hộ nghèo chỉ sở hữu trung bình $8958 \mathrm{~m}^{2} /$ hộ trong khi đó những hộ không nghèo hiện đang sở hữu trung bình 13529 m²/hộ.

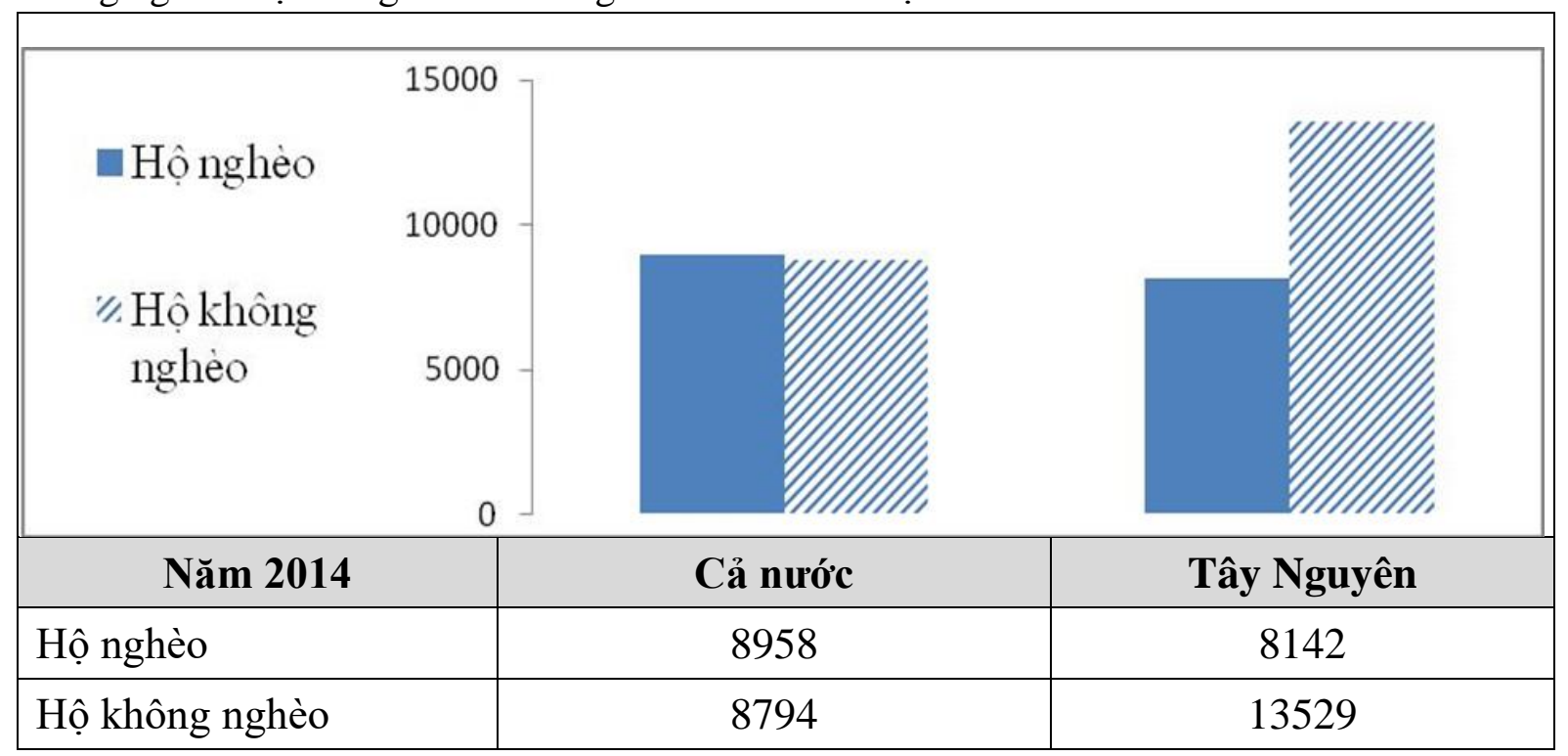

Hình 5. Biểu đồ so sánh về việc sở hữu đất trong sản xuất

Nguồn: Điều tra mức sống hộ gia đình năm 2014

\subsection{Kết quả hồi quy}

Sử dụng phần mềm Eviews để ước lượng hàm hồi quy logit với biến phụ thuộc thoát nghèo (THOAT) mang giá trị nhị phân. Nghiên cứu chọn tất cả các hộ nghèo vào thời điểm 2011, cho đến năm 2014 hộ gia đình nào đã thoát nghèo thì biến phụ thuộc nhận giá trị bằng 1 , chưa thoát nghèo thì bằng zero. Tác giả sử dụng hai mô hình hồi quy, trong đó mô hình 1 chạy riêng cho khu vực Tây Nguyên và mô hình 2 là chạy trên phạm vi cả nước để so sánh.

Kết quả phân tích tương quan giữa các biến độc lập cho thấy cả hai mô hình đều không xảy ra hiện tượng cộng tuyến. Mô hình 1 có hệ số McFadden R-square $=0.358$ trong khi mô hình 2 có hệ số này là 0.099 , điều này cho thấy dữ liệu của mô hình 1 phù hợp hơn so với mô hình 2 . Hầu hết dấu của các biến độc lập phù hợp với giả thuyết và cơ sở lý thuyết.

Về ý nghĩa của các hệ số, như đã trình bày ở phần mô hình hồi quy logit, nếu gọi xác suất để hộ gia đình thoát nghèo là $\mathrm{P}$ thì xác suất không thoát nghèo sẽ là 1-P (công thức 1). Trong điều kiện các yếu tố khác không đổi, nếu Xki tăng 1 đơn vị thì tỷ số log của hai xác suất sẽ thay đổi là $\beta \mathrm{k}$. Giá trị của tỷ số này được mô tả tại cột $\operatorname{Exp}(\mathrm{B})$ trong Bảng 1. 
Như vậy, dựa vào kết quả hồi quy, mô hình 1 có $\mathrm{P}_{\mathrm{i}}=0.2621$ và mô hình 2 có $\mathrm{P}_{\mathrm{i}}=0.3598$, kết quả hồi quy được giải thích như sau:

Anh hưởng tuổi tác: Kết quả hồi quy cho thấy mối quan hệ nghịch biến giữa tuổi của chủ hộ và xác suất thoát nghèo. Cụ thể, hệ số hồi quy có ý nghĩa về mặt thống kê và nếu tuổi của người chủ hộ gia đình tăng lên 1 thì xác suất thoát nghèo sẽ giảm $1,1 \%$ đối với khu vực Tây Nguyên và giảm $0.32 \%$ trên phạm vi cả nước. Kết quả này cũng phù hợp với nghiên cứu của Phan (2010) và nghiên cứu của Amaka (2011) ở Nigeria. Như vậy, sức trẻ, sự nhanh nhẹn, năng động của tuổi trẻ đã góp phần tăng xác suất thoát nghèo.

Anh huởng của giới tính: Người đứng đầu hộ gia đình có vai trò quan trọng trong việc quyết định sản xuất, kinh doanh. Kết quả hồi quy cho thấy mối quan hệ giữa giới tính và xác suất thoát nghèo có ý nghĩa về mặt thống kê. Theo đó, nếu chủ hộ là nam thì xác suất thoát nghèo ở khu vực Tây Nguyên sẽ tăng lên 7,6 lần và trên phạm vi cả nước sẽ tăng lên 1,454 lần. Kết quả này tương tự như nghiên cứu của Phan (2010) và nghiên cứu của Amaka (2011) ở Nigeria.

Anh hương nơi cu trú: Hệ số hồi quy ở khu vực Tây Nguyên cho thấy những hộ sống ở nông thôn có xác suất thoát nghèo thấp hơn, trong khi trên phạm vi cả nước thì có kết quả ngược lại. Tuy nhiên, kết quả này không có ý nghĩa về mặt thống kê.

Anh hương của yếu tố dân tộc học: Theo kết quả hồi quy, so với hộ gia đình người Kinh, xác suất hộ gia đình là người dân tộc thiểu số thoát nghèo thấp hơn 0,183 lần ở khu vực Tây Nguyên và 0,4 lần trên phạm vi cả nước. Kết quả này khá tương đồng với nghiên cứu về thoát nghèo ở Đồng Hỷ, Thái Nguyên của nhóm tác giả Dong và Chu (2017). Theo đó, xác suất hộ gia đình là người dân tộc thiểu số thoát nghèo giảm 0,109 lần so với hộ gia đình người Kinh.

Anh huởng của số thành viên phụ thuộc: Những gia đình đông thành viên sẽ làm giảm xác suất thoát nghèo. Tuy nhiên, số thành viên phụ thuộc tăng có thể nhận được nhiều trợ cấp của xã hội vì vậy lại làm tăng xác suất thoát nghèo. Nghiên cứu của N. H. Tran (2011) cho thấy, khi số người già và trẻ em trong hộ tăng lên một người thì xác suất nghèo trung bình của hộ tăng 2,8\%. Kết quả hồi quy của bài báo này là tương tự nhưng hệ số hồi quy không có ý nghĩa về mặt thống kê.

Anh hương trình độ: Theo kết quả hồi quy, khi trình độ giáo dục nâng lên một bậc thì xác suất thoát nghèo sẽ tăng $11,75 \%$ ở khu vực Tây Nguyên và $6,9 \%$ trên phạm vi cả nước. Kết quả này là tương đồng khi so với kết quả tăng thoát nghèo là $7,44 \%$ của biến trình độ do tác giả Dong và Chu (2017) thực hiện.

Anh hưởng tù̀ diện tích đất sản xuất: Khu vực Tây Nguyên, nơi mà đa phần người dân sống bằng sản xuất nông nghiệp, trồng trọt, thì việc sở hữu đất đai có vai trò quan trọng đối với xác suất thoát nghèo. Điều đặc biệt thú vị là hồi quy trên phạm vi cả nước thì mối quan hệ này không có ý nghĩa về mặt thống kê nhưng chỉ riêng khu vực Tây Nguyên thì mối quan hệ này rất chặt chẽ, hệ số tin cậy là rất cao, trên $99 \%$. Theo đó, nếu các yếu tố khác không đổi khi hộ gia đình ở Tây Nguyên tăng $1000 \mathrm{~m}^{2}$ đất sản xuất thì xác suất giảm nghèo sẽ tăng $1,7 \%$ (đổi từ đơn vị tính diện tích đất ban đầu là $\mathrm{m}^{2}$ ). Mối tương quan này cũng được minh chứng bởi các tác giả Cunguara (2008), Amaka (2011) và nghiên cứu của Dong và Chu (2017). 
Anh hương tù nhũng khoản hỗ trọ: Kết quả hồi quy cho thấy tồn tại mối quan hệ nghịch, tức hộ gia đình nhận được nhiều tiền hỗ trợ thì xác suất giảm nghèo lại giảm. Giải thích kết quả này tác giả cho rằng tuy ở mức nghèo đói nhưng mức độ thì rất khác nhau. Những hộ nhận được tiền tài trợ có thể thuộc diện rất khó khăn và vì vậy khoản hỗ trợ này không giải quyết được vấn đề thoát nghèo mà chỉ có thể có tác dụng làm giảm khó khăn của hộ nghèo. Ngoài ra còn có tâm lý ỷ lại của các hộ gia đình vào các chính sách của Chính phủ đối với diện hộ đói nghèo. Theo kết quả hồi quy, trong điều kiện các yếu tố khác không đổi, khi tiền hỗ trợ mà hộ nghèo nhận được tăng lên 1 triệu/năm thì xác suất thoát nghèo sẽ giảm 34,8\% ở khu vực Tây Nguyên và giảm 9,21\% trên phạm vi cả nước. Nghiên cứu của các tác giả Mai (2007), Phan (2010) cũng chỉ ra mối quan hệ giữa những chương trình hỗ trợ với xác suất thoát nghèo của người dân.

\section{Kết luận và khuyến nghị}

\subsection{Kết luận}

Từ bộ số liệu của VHLSS, nghiên cứu đã lọc ra 1195 hộ trên phạm vi cả nước, trong số đó gồm 103 hộ khu vực Tây Nguyên, thuộc diện hộ nghèo vào năm 2011. Cho đến năm 2014, trong số các hộ được chọn, đã có 430 hộ trên cả nước và 27 hộ ở khu vực Tây Nguyên thoát nghèo. Dựa vào số mẫu đã chọn tác giả sử dụng 8 biến độc lập để tìm hiểu các yếu tố ảnh hưởng tới xác suất thoát nghèo thông qua hai mô hình hồi quy logit nhị phân.

Kết quả cho thấy nhiều yếu tố ảnh hưởng tới xác suất thoát nghèo. Về tuổi của người chủ hộ gia đình càng cao thì xác suất thoát nghèo càng giảm. So với nữ, chủ hộ là nam giới sẽ tăng xác suất thoát nghèo. Nghiên cứu chỉ ra mối quan hệ đồng biến giữa trình độ học vấn cao nhất của thành viên trong hộ gia đình với xác suất thoát nghèo. Về dân tộc học, nghiên cứu cho thấy, so với người Kinh, người dân tộc thiểu số có xác suất thoát nghèo thấp hơn. Tuy nhiên, kết quả hồi quy không tìm thấy mối quan hệ có ý nghĩa về mặt thống kê giữa nơi cư trú và số thành viên phụ thuộc với xác suất thoát nghèo. Đặc biệt, kết quả hồi quy đã thêm một lần nữa minh chứng về vai trò của đất sản xuất với xác suất thoát nghèo. Điều đặc biệt thú vị là ở chỗ: nếu như trên phạm vi cả nước, mối quan hệ giữa sở hữu đất sản xuất nông nghiệp với thoát nghèo là không có ý nghĩa về mặt thống kê thì mối quan hệ này ở khu vực Tây Nguyên là rất chặt chẽ, hệ số tin cậy ở mức cao.

So với một số nghiên cứu trước thì điểm khác biệt của bài báo là thực hiện trên phạm vi một vùng hoặc cả nước, không chỉ cho một địa phương. Ngoài ra, nghiên cứu sử dụng phương pháp phân tích định lượng để khảo sát yếu tố tác động. Đặc biệt, tác giả đã minh chứng được vai trò của đất sản xuất đối với quá trình xóa đói giảm nghèo ở Tây Nguyên. Rõ ràng người dân ở Tây Nguyên sinh sống chủ yếu bằng nông nghiệp, trồng cây công nghiệp dài ngày như cà phê, cao su, chè, v.v... thì vai trò của đất sản xuất là rất quan trọng.

Mặc dù đã có nhiều cố gắng nhưng nghiên cứu còn nhiều điểm hạn chế, nhất là những hạn chế đến từ số liệu nghiên cứu và trải nghiệm của tác giả đối với đời sống xã hội của người dân nói chung và đời sống sinh hoạt của các hộ nghèo ở Tây Nguyên nói riêng. Đối với phân tích định lượng và sử dụng mô hình hồi quy thì vai trò của bộ số liệu khảo sát là rất quan trọng, tuy nhiên, dựa trên bộ số liệu VHLSS sẵn có, lượng thông tin mà tác giả có được là hạn chế. 


\subsection{Khuyến nghị}

Dựa trên kết quả nghiên cứu, tác giả đưa ra một số khuyến nghị nhằm cải thiện đời sống của người dân, tăng xác suất thoát nghèo.

Thứ nhất, về tổ chức, cần xác định công tác xóa đói giảm nghèo là một trong nhũng nhiệm vụ của nhiều tổ chức có liên quan. Kết quả hồi quy cho thấy có nhiều yếu tố ảnh hưởng tới việc xóa đói giảm nghèo như dân tộc, trình độ, tuổi tác, công tác tuyên truyền, v.v... chính vì vậy cần có sự lãnh đạo, chỉ đạo, phối hợp, kết hợp của chính quyền các cấp có liên quan đối với công tác giảm nghèo. Nói một cách khác, đói nghèo là vấn đề xã hội mà một tổ chức đơn lẻ sẽ không thể giải quyết triệt để được. Lồng ghép có hiệu quả các dự án, chương trình giảm nghèo cùng với chỉ đạo sâu sát của các cấp lãnh đạo thì công tác giảm nghèo thu được kết quả tốt.

Thứ hai, cần xây dụng chính sách đất đai hợp lý, đảm bảo đủ đất sản xuất cho hộ nghèo. Kết quả nghiên cứu cho thấy vai trò của sở hữu đất sản xuất đối với việc thoát nghèo là rất quan trọng ở khu vực Tây Nguyên. Để chương trình xóa đói giảm nghèo đạt kết quả tốt thì cần xây dựng những chính sách đất đai hợp lý cho từng nhóm đối tượng. Đặc biệt, khu vực này có nhiều đồng bào dân tộc thiểu số, cùng với địa hình miền núi cho thấy cần có nghiên cứu kỹ lưỡng cho công tác quy hoạch đất sản xuất, chính sách giao đất cho từng đối tượng, tránh tình trạng đất được giao nhưng không canh tác hoặc bị sang nhượng cho người khác, làm cho chính sách đất đai không phát huy tác dụng.

Thứ ba, cần xây dụng chính sách dân tộc, miền núi phù hợp, chú trọng đào tạo và đẩy mạnh công tác tuyên truyền, vận động toàn dân tham gia chương trình giảm nghèo. Như kết quả nghiên cứu cho thấy những hộ gia đình dân tộc thiểu số đều có xác suất thoát nghèo thấp hơn, vì vậy, Chính phủ cần có những chương trình thiết thực, phù hợp để giúp nhóm đối tượng này. Ngoài ra, kết quả nghiên cứu cho thấy việc trợ cấp bằng tiền mặt không giúp hộ dân thoát nghèo, trong khi đó, nghiên cứu lại chỉ ra tác động của yếu tố trình độ, tuổi tác. Như vậy ý thức vươn lên, phát huy nội lực là quan trọng đối với công tác xóa đói - giảm nghèo.

Tóm lại: Chương trình xoá đói giảm nghèo muốn đạt hiệu quả cao thì cần có sự vào cuộc của nhiều ban ngành, từ trung ương đến địa phương. Xây dựng và ban hành các chính sách hợp lý mà trong đó, ở khu vực Tây Nguyên, cần đặc biệt quan tâm đến chính sách đất đai, bảo đảm hộ nghèo có đất sản xuất và làm kinh tế. Ngoài ra cũng cần đẩy mạnh công tác tuyên truyền, vận động người dân cố gắng vươn lên, vượt khó, làm kinh tế hộ gia đình.

\section{Tài liệu tham khảo}

Amaka, A. C. (2011). Human capital investment and poverty reduction nexus in Nigeria. (Master's thesis). University of Economics, Nigeria.

Begg, D. (1991). Microeconomic (3rd ed.). New York, NY: McGraw-Hill.

Chowdbury, A. (2009). Microfinance as a poverty reduction tool - A critical assessment. (DESA Working Paper No.89). Retrieved December 12, 2017, from https://core.ac.uk/download/pdf/6301036.pdf 
Cunguara, B. A. (2008). Pathways out of poverty in rural Mozambique. (Master's thesis). Ann Arbor, MI: Michigan University.

Do, U. P. (2006). Khoa học và công nghệ trong sự nghiệp xóa đói giảm nghèo và phát triển bền vững [Science and technology in the cause of poverty reduction and sustainable development]. Tạp chí Cộng sản, 103.

Dong, D. V., \& Chu, N. T. K. (2017). Nguyên nhân ảnh hưởng tới thoát nghèo và tái nghèo của hộ nông dân huyện Đồng Hỷ, tỉnh Thái Nguyên [The reasons affecting poverty escape and falling back into poverty of farmers in Dong Hy district, Thai Nguyen province]. Tap chí Kinh tế và Quản Trị Kinh Doanh,3.

Gujarati, D. N. (2011). Econometrics by example. London, UK: Palgrave Macmillan.

Le, D. Q. (2011). Nghiên cứu các nhân tố ảnh hưởng đến nghèo ở Quảng Nam [Research on factors affecting poverty in Quang Nam]. (Master's thesis). Da Nang University, Da Nang, Vietnam.

Mai, H. T. T. (2007). Thưc trạng nghèo ở tỉnh Đồng Nai: Nhũng yếu tố tác động và giải pháp giảm nghèo [The reality of poverty in Dong Nai province: Factors affecting and solutions to poverty reduction]. (Master's thesis). University of Economics Ho Chi Minh City, Ho Chi Minh, Vietnam.

Nguyen, D. Q. (2002). Kinh tế lượng ứng dụng [Economical application]. In Giáo trình đại học Kinh tế quốc dân. Hanoi, Vietnam: NXB Đại học Kinh tế Quốc dân.

Nguyen, H. T. (2005). Nghiên cưu ứng dụng các mô hình kinh tế lương phân tích các nhân tố tác động đến nghèo đói và đề xuất xóa đói giảm nghèo ở các tỉnh Đông Nam Bộ [Research and apply econometric models to analyze factors affecting poverty and propose poverty reduction in the Southeast provinces]. Retrieved December 11, 2017, from http://digital.lib.ueh.edu.vn/handle/UEH/27862

Nguyen, N. T. (2012). Giải pháp xóa đói giảm nghèo nhằm phát triển kinh tế - xã hội ở các tỉnh Tây Bắc Việt Nam [Poverty alleviation solutions for socio-economic development in the Northwestern provinces of Vietnam]. (Doctoral dissertation). National Economics University, Hanoi, Vietnam.

Nguyen, T. V. (2004). Một số vấn đề kinh tế xã họi Việt Nam thời kỳ đổi mới [Some socioeconomic problems of Vietnam in the doi moi era]. Hanoi, Vietnam: Nhà xuất bản Chính trị Quốc gia.

Otsuka, K., Estudillo, J. P., \& Yamano, T. (2010). The role of labor markets and human capital in poverty reduction - Evidence from Asia and Africa. Asian Journal of Agriculture and Development, 7(1). 1-18.

Phan, N. T. (2010). Đánh giá tác động của tín dụng đối với giảm nghèo ở nông thôn Việt Nam [Assessing the impact of credit on poverty reduction in rural Vietnam]. (Master's thesis, Fulbright School of Public Policy and Management, Ho Chi Minh, Vietnam). Retrieved December 20, 2017, from https://fsppm.fulbright.edu.vn/vn/luan-van-mpp/danh-gia-tacdong-cua-tin-dung-doi-voi-giam-ngheo-o-nong-thon-viet-nam/ 
Reardon, T. (1997). Using evidence of household income diversification to inform study of the rural nonfarm labor market in Africa. World Development, 25(5), 735-747. doi:10.1016/s0305-750x(96)00137-4

Thai, H. V. (2007). Giải pháp xoá đói giảm nghèo trên địa bàn tỉnh Quảng Trị trong giai đoạn hiện nay [Solutions to poverty reduction in Quang Tri province in the current period]. (Master's thesis). Học viện Chính trị quốc gia Hồ Chí Minh, Hanoi, Vietnam.

Thủ tướng Chính phủ. (2012). Quyết định số 1489/QĐ-TTg ngày 08/10/2012 về việc phê duyệt chuơng trình muc tiêu quốc gia giảm nghèo bền vĩng giai đoạn 2012 - 2015 [Decision No. 1489 / QD-TTg dated October 8, 2012 approving the national target program for sustainable poverty reduction for the period 2012 - 2015]. Retrieved December 21, 2017, from

http://vanban.chinhphu.vn/portal/page/portal/chinhphu/hethongvanban?class_id=2\&_pa ge $=1 \&$ mode $=$ detail\&document_id $=163977$

Tổng cục Thống kê. (2014). Điều tra dân số 2014 [Census 2014]. Retrieved December 21, 2017, from www.gso.gov.vn/

Tổng cục Thống kê. (2014). Niên giám thống kê 2014 [Statistical yearbook 2014]. Ho Chi Minh, Vietnam: Nhà xuất bản Thống Kê.

Tran, H. N. (2011). Xóa đói giảm nghèo ở Kon Tum [Poverty reduction in Kon Tum]. (Master's thesis). Da Nang University, Da Nang, Vietnam.

Tran, T. C. (2007). Thục trạng và giải pháp xóa đói giảm nghèo cho đồng bào dân tộc vùng núi cao tỉnh Thái Nguyên [Current situation and solutions to poverty reduction for ethnic minority people in the highland areas of Thai Nguyen province]. Đề tài nghiên cứu cấp Bộ, Thai Nguyen Province, Vietnam.

UNDP. (2012). Báo cáo sáng kiến quản lý về giới và chính sách kinh tế ở châu Á-Thái Bình Dưong: Giới và đói nghèo [Asia-Pacific governance and economic policy initiative report: Gender and poverty]. Retrieved December 10, 2017, from https://www.undp.org/content/dam/vietnam/docs/Publications/6\%20Gioi\%20va\%20Doi \%20ngheo.pdf

USAID. (2006). Strengthening Mazambican capacity for agricultural productivity growth, policy analysis and poverty reduciton. Retrieved December 17, 2017, from https://docplayer.com.br/3420032-Strengthening-mozambican-capacity-for-agriculturalproductivity-growth-policy-analysis-and-poverty-reduction.html

Ủy ban nhân dân tỉnh Gia Lai, Kon Tum. (2016). Báo cáo "Chương trình giảm nghèo bền vĩng giai đoạn 2011-2015" của các tỉnh Gia Lai, Kon Tum [Report "Program of sustainable poverty reduction period 2011-2015” of Gia Lai and Kon Tum provinces]. Kon Tum Province, Vietnam: Ủy ban nhân dân tỉnh Gia Lai, Kon Tum.

Văn phòng điều phối chương trình 135 - Vụ Chính sách - Ủy ban dân tộc. (2011). "Giảm nghèo bền vũng giai đoạn 2011-2015 và co chế tổ chức thực hiện đối với vùng dân tộc thiểu số và Miền núi" Website chuoong trình 135 ["Sustainable poverty reduction in the 2011 - 
2015 period and the implementation mechanism for ethnic minorities and mountainous areas" Program website 135]. Hanoi, Vietnam: Vụ Chính sách -Ủy ban dân tộc.

World Bank. (2015). Ending poverty and sharing prosperity. Retrieved December 18, 2017, from http://pubdocs.worldbank.org/en/637391444058280425/GMR-2014-FullReport.pdf 